Journal of Advanced Research in Fluid Mechanics and Thermal Sciences

\title{
Effect Of Position and Design Parameters of a Fan-Cooled Cold Side Heat Sink of a Thermoelectric Cooling-Module on The Performance of a Hybrid Refrigerator
}

\author{
Yasser Abdulrazak Alghanima ${ }^{1,}{ }^{*}$, Osama Mesalhy², Ahmed Farouk Abdel Gawad² \\ Mechanical and Electrical Faculty, Alfurat University, Deir Ezzor, Syria \\ Mechanical Power Engineering Department, Faculty of Engineering, Zagazig University, Zagazig, 44519, Egypt
}

\section{ARTICLE INFO}

\section{Article history:}

Received 10 May 2021

Received in revised form 26 June 2021

Accepted 3 July 2021

Available online 6 August 2021

\section{Keywords:}

CFD analysis; hybrid householdrefrigerator; vapor-compression cooling; thermoelectric cooling; fan direction; number of fins

\section{ABSTRACT}

\begin{abstract}
This paper presents a CFD and experimental study of the thermal behavior of the thermoelectric-compartment in a hybrid household-refrigerator that combines thermoelectric and vapor-compression technologies. The hybrid refrigerator has three compartments. One of them is driven by a thermoelectric cooling system, which was made of one Peltier module and two fan-cooled heat sinks mounted on the hot and cold sides. The simulation results were compared with experimental measurements and showed a good agreement. The performance of the thermoelectric refrigerator was tested with changing the pushing direction. Two pushing directions for the fan were examined. In the first one (direction-I), the fan was fixed such that it sucked the air beside the cold heat sink. While in the second direction (direction-II), the fan was assumed to be flipped to push the air over the cold-side heat sink. The results showed that the second fan direction (direction-II) is more effective for heat transfer mechanism between the cold-side heat sink and the inside air of the thermoelectriccompartment.
\end{abstract}

\section{Introduction}

Nowadays, refrigeration applications are gaining more importance. They are used in all sectors of industrial, commercial, and housing as refrigeration has become necessary in different technological processes. The cooling is achieved by using one of the conventional refrigeration systems such as vapor-compression refrigeration systems (VCRS), or the modern refrigeration systems such as thermoelectric-refrigeration system (TERS), which were not available commercially until after the mid-1990s [1]. VCRS are the most used in industrial applications, and household refrigerators because of their high coefficient of performance (COP), especially in the high cooling capacities. VCRS use refrigerants as working fluids. The worst disadvantage of VCRS is the high level for global warming potential (GWP), and ozone depletion potential (ODP). Thus, they have adverse effects on the world climate worldly climate like the effect of burning fossil fuels (sources of non-renewable energy) to

\footnotetext{
* Corresponding author.

E-mail address: yasser-al-ghanime@hotmail.com
}

https://doi.org/10.37934/arfmts.85.2.6679 
generate energy and electricity [2,3]. Consequently, many protocols were established such as Kyoto (Japan 1997) aiming at forbidding the use of these refrigerants. Another problem that faces the use of VCRS is the oscillation in the inner temperature of the refrigerator, which is more than $8{ }^{\circ} \mathrm{C}$, because of the on/off operation nature of the compressor [4]. This oscillation in temperature is very damaging, especially on preserving perishable goods, food, and medicines. Actually, there are few solutions such as using an improved-temperature control-system with VCRS, which have fixed speed compressors [5], or using an electronic-expansion valve with variable-speed compressors [6]. But this makes VCRS more complex and less competitive in the markets. Therefore, the researchers focus their efforts on developing new alternative refrigeration, environmental-friendly, technologies. One of the new alternatives is the thermoelectric-refrigeration systems (TERS) that have various advantages, namely: no moving parts, less noise, and environment friendly [7]. Moreover, it can be improvement of the coefficient of performance of thermoelectric refrigerator by using new technologies are mounted on the hot side of it, which have high rates for heat transfer like heat pipe or cooling plate mini channels [8]. The essential benefit of TERS is their high temperature-control. The temperature fluctuation of an interior, cooled by TERS, is lower than $0.4{ }^{\circ} \mathrm{C}$ [9].

The thermoelectric refrigerator (TER), or Peltier refrigerator is defined as a solid-state device that uses electrical energy to produce cooling effect according to the Peltier effect, 1834 [10]. TER consists of a Peltier module (PM), and two heat sinks that are attached to the two sides of the Peltier module. Each Peltier module is made of many thermoelectric pairs, which are made from thermoelectric materials (P-type, and $\mathrm{N}$-type). These pairs are connected electrically in series and thermally in parallel. The electric pairs are sandwiched between two ceramic substrates [10].

Many studies investigated the performance of the TERS. One of these studies simulated the thermal performance of TER at different operating conditions using MATLAB [11]. Their results demonstrated that COP of TER increases if the temperature difference between the heat source and heat sink decreases. Another investigation, conducted by Bansal and Martin [12], compared the performance of three refrigeration systems (VCR, TER, and absorption refrigeration system (AR)) that were used in a household refrigerator. Their experiment showed that the VCR system had the best performance with COP of 2.59. COPs of TER and AR were 0.59, and 0.47, respectively. Moreover, using the TER, as an independent cooling-system in household refrigerators, attracted the researchers to benefit from their advantages. An experimental study and a performance simulation of TER were carried out by Astrain et al., [13]. They carried out design and construction of a prototype with the development of a computational model for the thermoelectric refrigerator. They focused on the analysis of electric power consumption of TER. They found that TER consumed two times more than VCR at the same conditions. Another experimental investigation concerned the effect of the position of Peltier module (model TEC1-12706) on the different walls of the thermoelectric compartment [14]. Their results showed that the best location of Peltier module was on the sidewall with COP decrease with the time. On the other hand, the influence of using different temperaturecontrol systems on the performance of TER was experimentally investigated by Martínez et al., [15]. Their study was based on three controlling methods, namely: the idling voltage, on/off controller system, and proportional integral-derivative controller. Their experiment demonstrated that using the idling voltage system resulted in increasing COP by $64 \%$ with decreasing the energy consumption by $32 \%$. Many studies investigated the performance enhancement of household refrigerators that are driven by VCRS such as Belman-Flores et al., [16], which presented a review of the researches of the greatest impact on household refrigeration such as thermal stratification, environmentally innocuous refrigerants, and hybrid systems. Another paper reported a review of householdrefrigerator technologies, including vapor-compression, absorption, thermoelectric, and thermoacoustic [17]. 
Utilization of computational fluid dynamics (CFD), to simulate the household refrigerators, attracted many researchers as the method successfully predicts velocity air distribution and temperature stratification inside the compartments of the household refrigerators. One of these papers [18] presented an experimental and CFD analysis for flow and thermal behavior inside the chamber of an absorption refrigerator. A similar study was conducted by Belman-Flores et al., [19], which included analysis of temperature stratification due to forced convection inside a bottommount freezer, and a fresh-food compartment of a household refrigerator. A mathematical model was developed and verified for a household refrigerator under different conditions was carried out by Ledesma and Belman-Flores [20]. Few studies investigated the effect of hybridization of both thermoelectricity, and vapor-compression technologies in household refrigerators. One research [21] presented a numerical and experimental investigation of hybrid household-refrigerator (HHR) with three compartments; one of them was cooled by TER. The investigation focused on the energy consumption of the hybrid refrigerator when the TER was located at different positions inside the hybrid refrigerator. The results showed a decrease in energy consumption by $10 \%$ and $27 \%$ when the ambient temperature was $16^{\circ} \mathrm{C}$, and $32^{\circ} \mathrm{C}$, respectively. A similar study investigated the energy consumption of hybrid household-refrigerator [9]. They concluded that the hybrid refrigerator was at "Class A"-energy efficiency.

Based on the previous survey, it can be noted that there are limited simulation studies that have been performed to predict of the air distribution and temperature stratification inside the thermoelectric-compartment in the hybrid household-refrigerators. Therefore, this study aims to develop a hybrid household-refrigerator of three compartments with analyzing the thermal behavior inside the thermoelectric-compartment in case of changing the pushing direction of the cold side fan.

\section{Experimental Analysis}

\subsection{Specifications of the Hybrid Household-Refrigerator (HHR)}

To develop the hybrid household-refrigerator, a vapor-compression domestic refrigerator of a top-freezer type with two compartments (freezer, and cooler compartment), and two doors was used. The household-refrigerator had one compressor, coil-condenser in the back wall, and an evaporator. Specifications of the refrigerator are shown in Table 1.

Table 1

Specifications of the VCR household-refrigerator

\begin{tabular}{ll}
\hline Specifications & Value \\
\hline Total capacity & 330 Liters \\
Freezer capacity & 82.5 Liters \\
Cooler capacity & 247.4 Liters \\
Refrigerant & R $134 a$ \\
Refrigerant charge & $0.160 \mathrm{~kg}$ \\
Energy consumption & $2.3 \mathrm{kw} . \mathrm{h} /$ day \\
Climate classes & $\mathrm{T}$ \\
Defrosting type & Defrost \\
Indoor dimensions $(\mathrm{W} \times \mathrm{D} \times \mathrm{H})$ & $620 \times 630 \times 1645 \mathrm{~mm}$ \\
\hline
\end{tabular}

The cooler compartment was divided into two divisions. The first was named as thermoelectriccompartment (TER compartment), which was cooled by TER. The second was named as fresh-food compartment, Figure 1. 


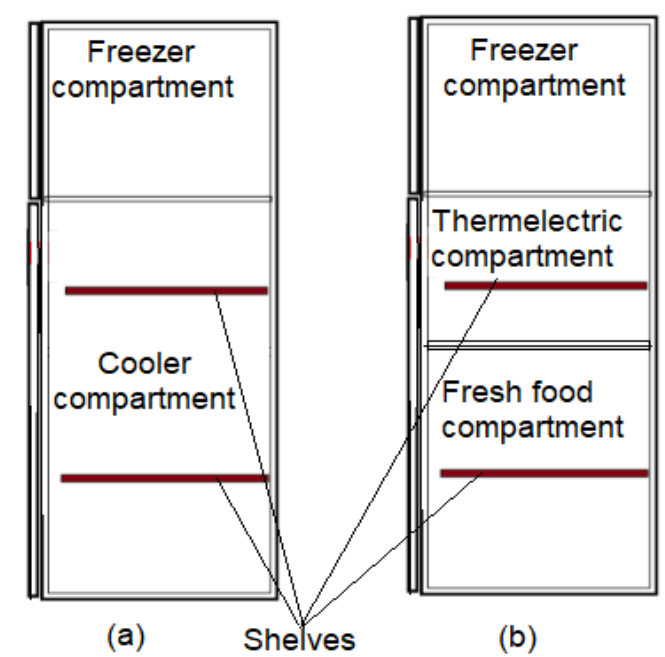

Fig. 1. Household-refrigerator: (a) before, and (b) after adding the thermoelectriccompartment

The TER compartment had an inner volume of $57 \times 10^{-3} \mathrm{~m}^{3}$ with dimensions of $300 \mathrm{~mm} \times 450$ $\mathrm{mm} \times 420 \mathrm{~mm}$ for $\mathrm{H} \times \mathrm{W} \times \mathrm{D}$. It contains a shelf of dimensions $4 \mathrm{~mm} \times 444 \mathrm{~mm} \times 340 \mathrm{~mm}$, which was made from glass, and was mounted at height $100 \mathrm{~mm}$ from the bottom wall of TEC. Table 2 shows the wall thicknesses of the thermoelectric-compartment after insulating the walls using polyurethane, and polystyrene. Properties of these materials are shown in Table 3.

Table 2

Wall thicknesses of the thermoelectric-compartment

\begin{tabular}{ll}
\hline The wall & Value \\
\hline Ceiling wall & $0.060 \mathrm{~m}$ \\
Bottom wall & $0.040 \mathrm{~m}$ \\
Back wall & $0.085 \mathrm{~m}$ \\
Front door & $0.080 \mathrm{~m}$ \\
Lateral walls & $0.075 \mathrm{~m}$ \\
\hline
\end{tabular}

Table 3

Properties of the insulation materials of the thermoelectric-compartment [21]

\begin{tabular}{llll}
\hline The material & $\mathrm{P}\left[\mathrm{kg} / \mathrm{m}^{3}\right]$ & $\mathrm{Cp}[\mathrm{J} / \mathrm{kg} . \mathrm{K}]$ & $\mathrm{K}[\mathrm{W} / \mathrm{m} . \mathrm{k}]$ \\
\hline Polystyrene & 26.25 & 1,200 & 0.0345 \\
Polyurethane & 34.5 & 1,500 & 0.022 \\
\hline
\end{tabular}

One Peltier module (type TEC1-12706), with dimensions $40 \mathrm{~mm} \times 40 \mathrm{~mm} \times 3.8 \mathrm{~mm}$ of $50 \mathrm{~W}$-cooling capacity as shown in Figure 2(b) [22], was used in the thermoelectric-compartment. The maximum DC supply was 12 volts with a maximum current of 5.8 amperes. A heat sink of 20 fins, with dimensions $78 \mathrm{~mm} \times 78 \mathrm{~mm} \times 38 \mathrm{~mm}$ (Length (L) $\times$ Width $(W) \times$ Height $(\mathrm{H})$ ) and base-thickness of $8 \mathrm{~mm}$, was mounted on the cold-side of the Peltier module. Each fin had dimensions of $30 \mathrm{~mm} \times 78 \mathrm{~mm} \times 2$ $\mathrm{mm}$ (Length $(\mathrm{L}) \times$ Width $(\mathrm{W}) \times$ Thickness $(\delta)$ ). A fan, with diameter $72 \mathrm{~mm}$ (type Cooler Master CM 12V) as shown in Figure 2(a) [23], was mounted on the cold-side heat sink. On the hot-side of the Peltier module, a heat sink of dimensions $120 \mathrm{~mm} \times 100 \mathrm{~mm} \times 21 \mathrm{~mm}$ (Length $(L) \times$ Width $(W) \times$ Thickness $(\delta)$ ) was mounted. It has 23 fins, each fin had dimensions $20 \mathrm{~mm} \times 100 \mathrm{~mm} \times 1 \mathrm{~mm}$ (Length (L) $\times$ Width 
(W) $\times$ Thickness ( $(\delta))$, and a $72 \mathrm{~mm}$-diameter fan as shown in Figure 2(c) [23]. The constructed hybrid household-refrigerator, and configuration of thermoelectric cooler (TEC) are shown in Figure 3.

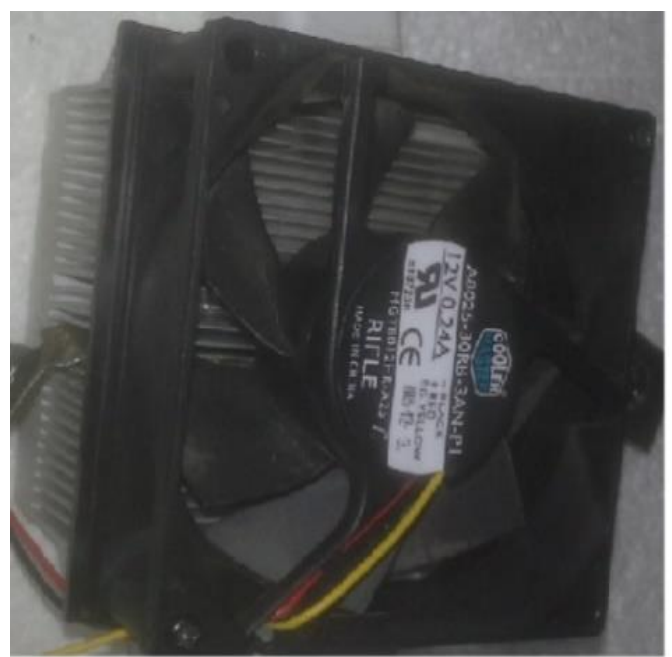

(a)

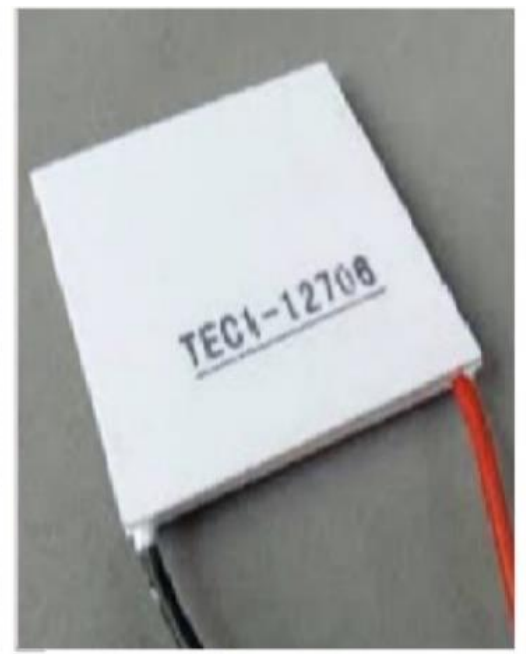

(b)

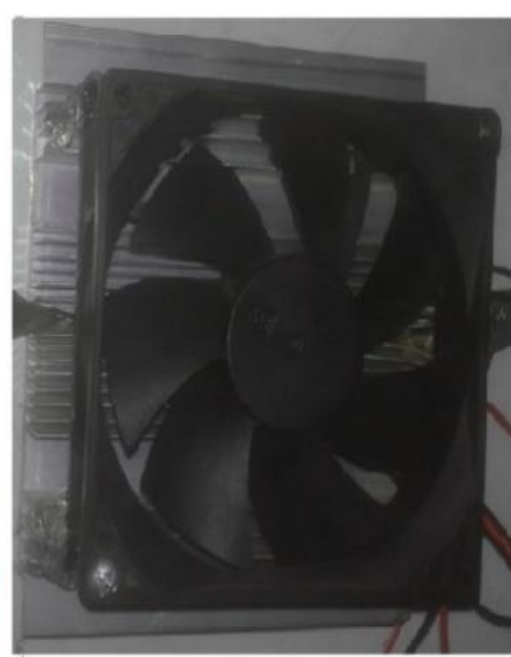

(c)

Fig. 2. Configuration of (a) interior heat sink, (b) Peltier module, and (c) outside heat sink [22,23]

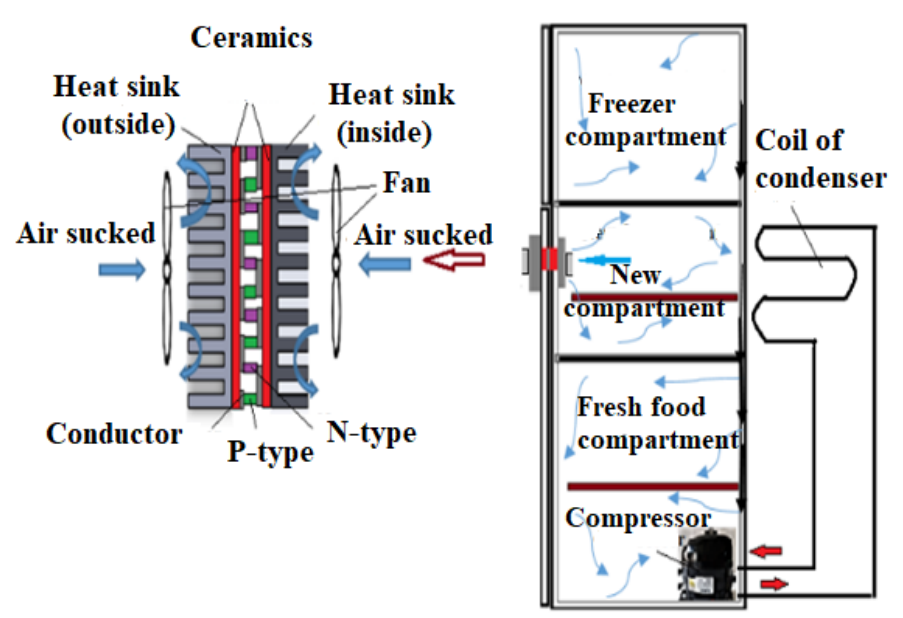

Fig. 3. Hybrid household-refrigerator (HHR)

\subsection{Measuring Instruments}

RXN Linear DC Stabilized-Voltage Power Supply type RXN-3010D was used to supply the Peltier module, and the two fans with DC current. The input voltage to the RXN power supply was AC $220 \mathrm{~V} \pm$ $10 \%$ with $50 \mathrm{~Hz}$. It has an output-voltage ranging from 0 to 30 Volts with stabilized degree $\leq 0.05 \%$. The output DC electric current was ranging from 0 to 10 Ampere with stabilized degree $\leq 0.2 \%$ as shown in Figure 4(a) [24]. Digital Temperature Panel Meters type TPM-30 were used to measure of the temperature at different locations inside the thermoelectric-compartment. The meters had measuring range -50 to $+110^{\circ} \mathrm{C}$ with accuracy $\pm 0.5^{\circ} \mathrm{C}$ as shown in Figure $4(\mathrm{~b})$. 


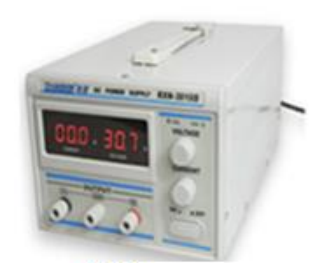

(a)

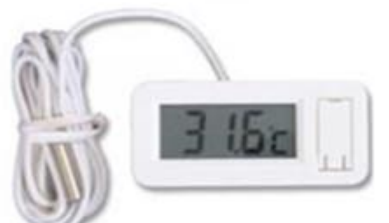

(b)

Fig. 4. Measuring instruments [24]

To prepare for the experimental test, the hybrid refrigerator was maintained in the operating mode for more than 24 hours to reach the steady-state temperature. Then, the temperature distribution of the compartments, walls, and ambient air were recorded with time. The time interval between measurements was one minute. The experiment continued until the measured temperature reached steady-state condition.

\section{Computational Analysis}

Aim of this computational analysis is to predict the air flow and temperature distribution inside TER compartment in order to determine the optimum installation position for the cold-side fan of the TER in the case of empty compartment with one shelf and unloaded refrigerator. The numerical analysis was based on solving the conservation equations of mass, momentum, and energy. The following assumptions were made

i. The flow was assumed steady and turbulent

ii. Natural convection and radiation effects were negligible

iii. The air was treated as incompressible fluid

\subsection{Governing Equations}

Based on the above assumptions, the conservation equations of mass, momentum, and energy for the fluid take the following form [25]

Continuity equation (conservation of mass)

$\nabla \cdot \vec{V}=0$

where $\vec{V}$ and $\nabla$ are the velocity of flow, and the gradient operator, respectively.

Navier-Stokes equations (Conservation of momentum)

$\rho \frac{D \vec{V}}{D t}=-\nabla p+\mu \nabla^{2} \vec{V}$

where $\frac{D}{D t}$ is the substantial derivative, $\nabla^{2}$ is the Laplacian operator, $\rho$ is the fluid density, $\mu$ is dynamic viscosity coefficient, and $\mathrm{p}$ is the static pressure. 


\section{Conservation of energy}

$$
\rho \cdot c_{p} \cdot \frac{D T}{D t}=k \cdot \nabla^{2} T
$$

where, $c_{p}$ is the heat capacity at constant pressure, $k$, and $T$ are the thermal conductivity, and temperature of the fluid, respectively. In solid regions such as the heat sink and the shelf, only the heat diffusion equation is solved.

$$
k_{s} \cdot \nabla T=0
$$

where, $k_{s}$ is the thermal conductivity of the solid material. The effect of turbulent fluctuations was modelled using standarded k- $\varepsilon$ model [26], and the near-wall regions were treated using the standard wall function.

\subsection{Geometrical Model and Computational Mesh}

The geometrical model, which included the air inside the TER compartment, the cold-side heat sink, and the shelf, represents the computational domain. The model was constructed by Solidworks software and exported to the ANSYS Design Modeler for meshing and computing. Due to the geometrical symmetry of the TER compartment, only half of the geometry was considered in order to save computational time and memory requirements as shown in Figure 5 . The fan of the cold-side heat sink was not considered in this simulation. Instead of solving the flow through the rotating fan, the fan was represented by an interface plane. At this plane, the relation between the static pressure jump and the volume flow-rate was specified as shown in Figure 6.

The computational mesh was made using the ANSYS AUTODYAN. Details of the generated mesh are shown in the Table 4. A mesh sensitivity study was carried out to ensure that the results are not affected by the number of cells. Thus, the number of cells was gradually increased from $2,000,000$ to $6,500,000$ cells. Only, the minimum cell size and maximum face size were changed, and the rest of the mesh parameters were not changed. A mesh size of about 5,900,000 was found to be satisfactory in this simulation.
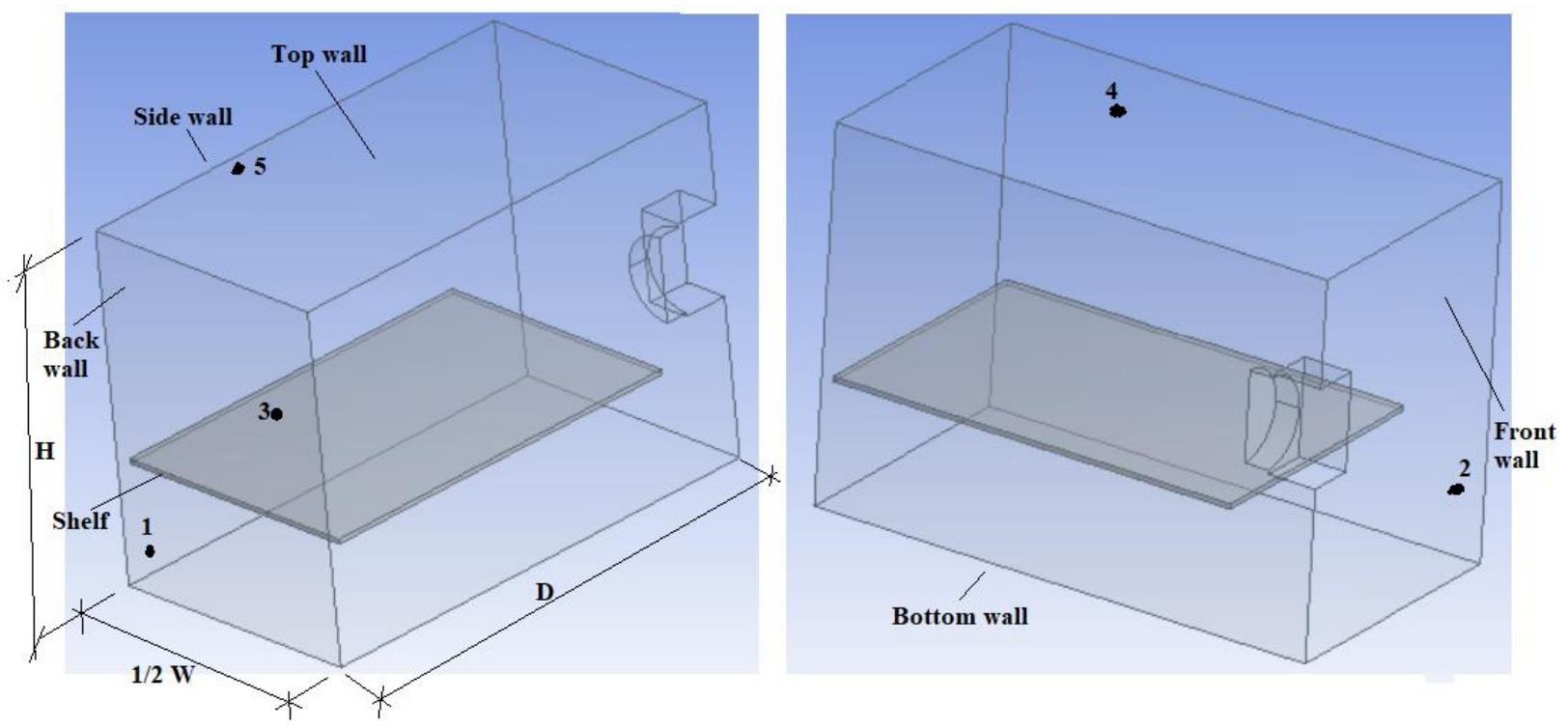

Fig. 5. Geometry of the computational model 


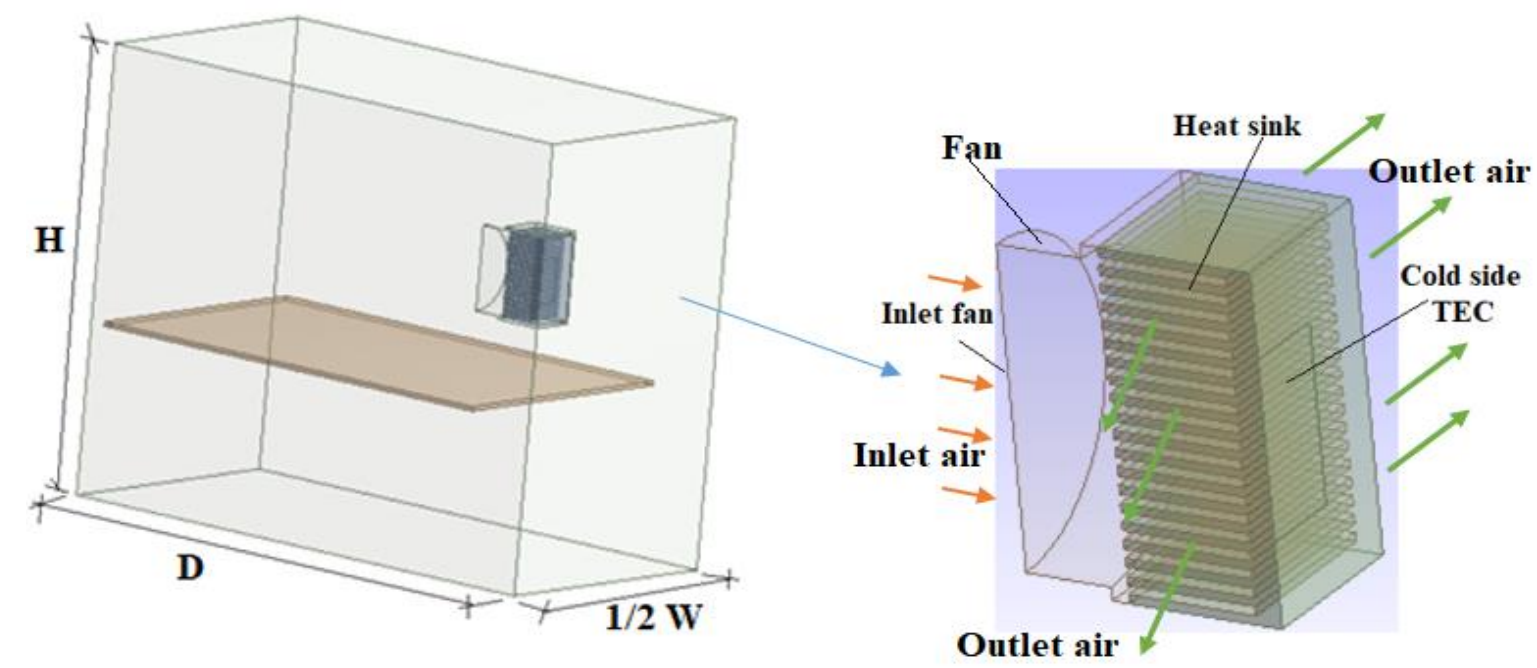

Fig. 6. Simplified geometry model of finned heat sink cold side of TER

Table 4

Properties of the generated mesh

\begin{tabular}{lll}
\hline Parameters & & Value \\
\hline Body and shelf of refrigerator & Sizing & \\
& Size function & Curvature \\
& Relevance centre & Fine \\
& Transition & Slow \\
& Span angle centre & Fine \\
& Curvature normal angle & $18^{0}$ \\
& Min size $[\mathrm{m}]$ & $0.12 \times 10^{-3}$ \\
& Max face size $[\mathrm{m}]$ & $2.30 \times 10^{-3}$ \\
& Max tet size $[\mathrm{m}]$ & $450 \times 10^{-}$ \\
Heat sink & Sizing & \\
& Size function & Element size \\
& Type & $1 \times 10^{-3}$ \\
& Element size $[\mathrm{m}]$ & $0.1 \times 10^{-3}$ \\
& Local min size $[\mathrm{m}]$ & $0.1 \times 10^{-3}$ \\
Quality & Proximity min size $[\mathrm{m}]$ & Element size \\
Statistics & Smoothing & Medium \\
& Nodes & $1,254,224$ \\
& Elements & $5,903,318$ \\
\hline
\end{tabular}

\subsection{Numerical Scheme and Boundary Conditions}

The pressure-based solver was selected. SIMPLE algorithm was used to couple the pressure and velocity fields. Also, second-order for pressure and second-order upwind discretization was used for momentum, and turbulent kinetic energy while first-order discretization was considered for the turbulent dissipation rate. The thermophysical properties of the materials in the fluid and solid regions of the computational domain were specified as shown in Table 5 [21].

Table 5

Thermophysical properties of the materials in the model [21]

\begin{tabular}{lllll}
\hline Materials & & $\mathrm{P}\left[\mathrm{kg} / \mathrm{m}^{3}\right]$ & $\mathrm{Cp}[\mathrm{J} / \mathrm{kg} . \mathrm{K}]$ & $\mathrm{K}[\mathrm{W} / \mathrm{m} . \mathrm{k}]$ \\
\hline Fluid & Air & 1.225 & $1,006.43$ & 0.0242 \\
Solid & Aluminium & 2719 & 871 & 202.4 \\
& Glass & 2500 & 791 & 1.05 \\
\hline
\end{tabular}


No-slip condition was assumed at all the walls except the fan interface-plane, where pressure jump of 17.56 Pa was considered according to the data provided by the manufacturing company [23]. For thermal boundary conditions, a convection boundary was assumed at the bottom, top, front, back, and right walls of the TER compartment as shown in Table 6 . The heat flux at these walls is defined from

$$
q^{\prime \prime}=U \cdot\left(T_{w}-T_{a}\right)
$$

where, $U$ is the heat-transfer coefficient, which accounts for the conduction and the outer convection, and $T_{a}$ is the outer ambient temperature.

$$
\frac{1}{U}=\frac{e}{k_{w}}+\frac{1}{h}
$$

where, the first term in the right-hand side represents the conduction thermal-resistance of the wall, and the second term represents the outer convection thermal-resistance. e and $k_{w}$ are the thickness, and the thermal conductivity of the wall, respectively. Free-convection correlations were used to estimate the outer convection heat-transfer coefficient, $h$ [25]. For vertical walls (back, front, and right walls), the Nusselt number is defined as

$$
N u=\frac{U . L_{c}}{k}=\left\{0.825+\frac{0.387 R a_{L}^{\frac{1}{6}}}{\left[1+(0.492 / \mathrm{Pr})^{9 / 16}\right]^{\beta / 27}}\right\}^{2}
$$

where, $\mathrm{Ra}, \mathrm{Pr}$, and $L_{c}$ are the Rayleigh number, Prandtl number, and the wall characteristic length, respectively. For horizontal walls (top and bottom walls), the Nusselt number is defined from

Top wall: $N u=0.54 R a_{L}^{1 / 4}$

Bottom wall: $N u=0.27 R a_{L}^{1 / 4}$

Rayleigh number is given by,

$R a_{L}=G r_{L} \cdot \operatorname{Pr}$

where, Gr is Grashof number. Gr and Pr are given by

$$
\begin{aligned}
& G r_{L}=\frac{g \cdot \beta\left(T_{s}-T_{a}\right) \cdot L_{c}^{3}}{v^{2}} \\
& \operatorname{Pr}=\frac{v}{\alpha}
\end{aligned}
$$

where, $\beta$ is the coefficient of volume expansion, and $v$ is the kinematic viscosity of the air. $T_{a}$ is ambient temperature, and the estimated heat-transfer coefficient $(U)$ at each wall are listed in Table 6. The cold-side of the Peltier module was considered as an isothermal wall of temperature 275.3K. 
The solution was deemed to be converged when the residuals for continuity and velocities became less than $10^{-3}$, and less than $10^{-6}$ for energy equation.

Table 6

Boundary condition for the thermoelectric-compartment

\begin{tabular}{lllllllll}
\hline Boundary & & Thermal conditions & $\mathrm{T}_{\mathrm{a}}[\mathrm{K}]$ & $\mathrm{U}\left[\mathrm{W} / \mathrm{m}^{2} . \mathrm{K}\right]$ & $\mathrm{P}[\mathrm{Pa}]$ & $\mathrm{T}_{\mathrm{c}}[\mathrm{K}]$ & $\mathrm{q}\left[\mathrm{W} / \mathrm{m}^{2}\right]$ & $V[\mathrm{~m} / \mathrm{s}]$ \\
\hline Air inlet & & Fan & - & & 17.56 & - & - & - \\
Air outlet & Walls- & & & & & & \\
& Front wall & Convective & 297.3 & 0.50 & - & - & - & No slip \\
& Back wall & Convective & 304.2 & 0.42 & - & - & - & No slip \\
& Right wall & Convective & 297.3 & 0.43 & - & - & - & No slip \\
& Top wall & Convective & 276.5 & 0.36 & - & - & - & No slip \\
& Bottom wall & Convective & 284.2 & 0.45 & - & - & - & No slip \\
Heat sink & Back wall & Heat flux & - & - & - & - & 0 & - \\
TEC & Cold side wall & Temperature & - & - & - & 275.3 & - & - \\
\hline
\end{tabular}

\section{Computational Model Validation}

The predicted temperature field that was obtained from the computational model was compared with the temperature measurements. The temperatures at 5 points inside the thermoelectriccompartment were monitored and compared with the measurements. The locations of the monitored points are shown in Figure 5. The results showed a good agreement. The maximum difference between the measured and predicted values does not exceed $2.05{ }^{\circ} \mathrm{C}$, Table 7 .

Table 7

Measured and predicted temperatures at different locations in the TEC compartment

\begin{tabular}{llll}
\hline Temperature & Texperiment $[\mathrm{K}]$ & $\mathrm{TCFD}_{\mathrm{K}}[\mathrm{K}]$ & $\Delta \mathrm{T}[\mathrm{K}]$ \\
\hline T1 & 278.16 & 280.13 & 1.97 \\
T2 & 274.88 & 276.28 & 1.40 \\
T3 & 278.14 & 279.32 & 1.18 \\
T4 & 273.90 & 275.95 & 2.05 \\
T5 & 277.40 & 276.30 & -1.1 \\
\hline
\end{tabular}

\section{Results and Discussions}

As mentioned above, this work focuses on investigating the temperature field inside the thermoelectric-compartment for different pushing directions, and different rotational speed (rpm) of the cold-side fan. Two pushing directions for the fan were examined. In the first one (direction-I), the fan was fixed such that it sucked the air beside the cold-side heat sink and pushed it inside the thermoelectric-compartment. In the second fan direction (direction-II), the fan was assumed to be flipped such that it sucked the warm air inside the thermoelectric-compartment and pushed it over the cold-side heat sink.

\subsection{Effect of Pushing Direction of the Cold-Side Fan}

The computational simulation was performed for the two fan directions. In each case, the computational mesh, the model, and the solution parameters were kept the same. 


\subsubsection{Pushing direction-I of the fan}

Air streamlines for the first pushing direction of the fan is presented in Figure 7. It can be observed that there are intense streamlines in the upper division of the thermoelectric-compartment, which was located between the shelf and the top wall. Velocity of the air at the outlet of the fan is relatively high $(2.5$ to $3.5 \mathrm{~m} / \mathrm{s})$. Then, it is started to decrease as the air spread inside the thermoelectriccompartment. It can be demonstrated that the shelf had a negative effect on the air distribution. The shelf prevented the air from flowing in the bottom region of the thermoelectric-compartment.
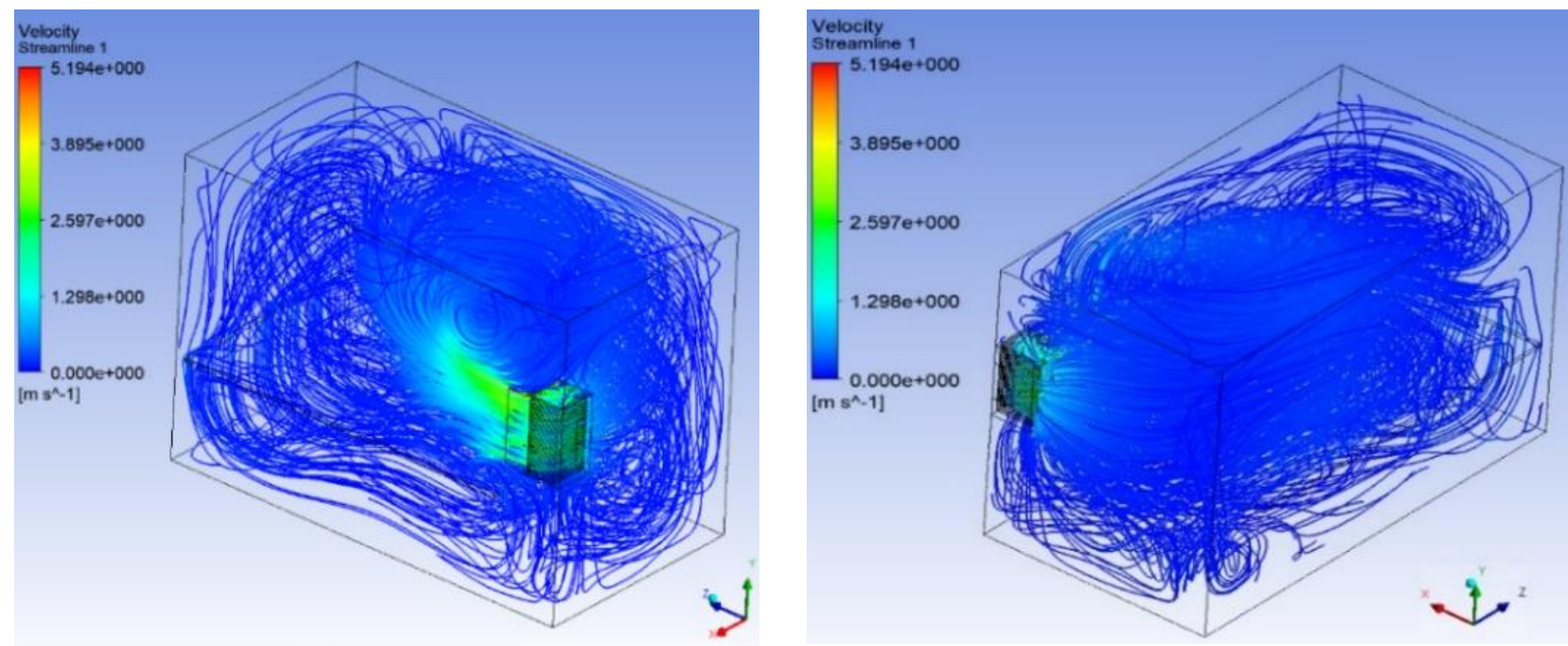

Fig. 7. Air streamlines for pushing direction-l of the fan

Temperature distribution inside the thermoelectric-compartment for first fan direction is shown in Figure 8. It can be observed that the region near the fan outlet had the coldest air with a temperature of about $275.7 \mathrm{~K}$. The temperature of the region beside the top wall had a temperature of about $277 \mathrm{~K}$. The regions of the higher temperature values were spread near the back wall and in the region under the shelf. Also, it can be demonstrating that the presence of the shelf had a negative effect on the temperature distribution because it had a low thermal-conductivity and prevented the cold air from reaching the bottom region.
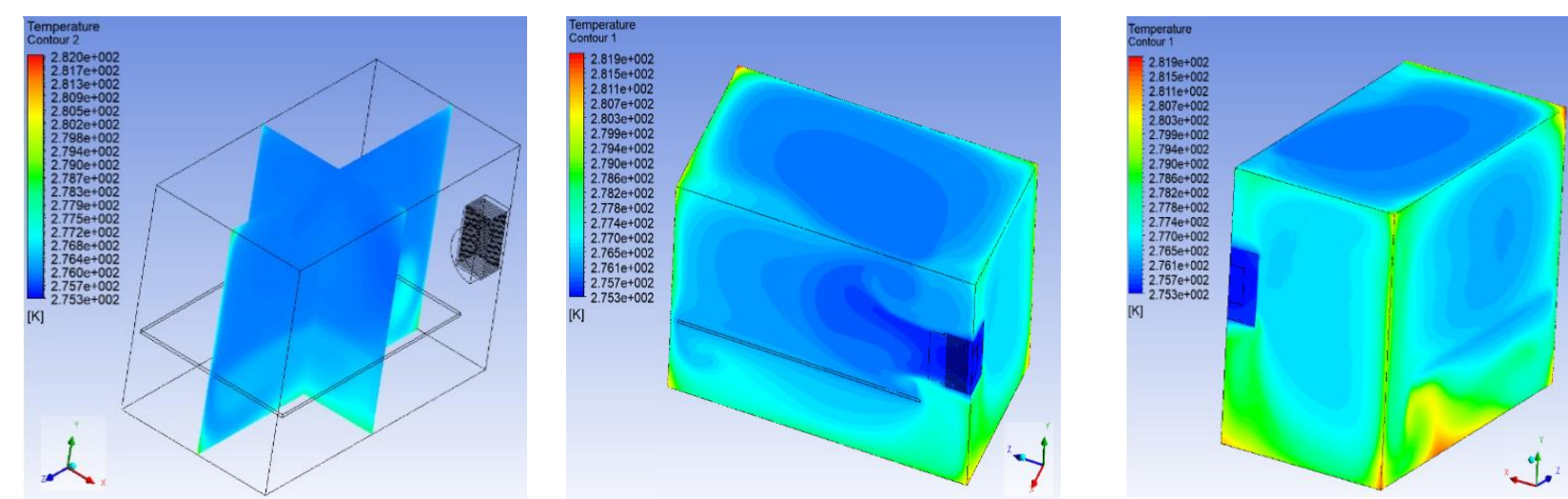

Fig. 8. Temperature distribution inside the TER compartment for pushing direction-I of the fan 


\subsubsection{Pushing direction-ll of the fan}

Figure 9 shows the flow streamlines for the second pushing direction of the fan, where the fan sucked the warm air from the thermoelectric-compartment and blowed it to impinge the cold- side heat sink. The air velocity at the fan outlet reached a value of about $2 \mathrm{~m} / \mathrm{s}$. Upon impinging with the heat sink, the air flowed through the channels between the fins towards the side walls and generated two big vortices; one at the upper part and the second in the lower part of the thermoelectriccompartment as shown in Figure 9. Temperature distribution inside the thermoelectriccompartment for the second pushing direction of the fan is shown in Figure 10.
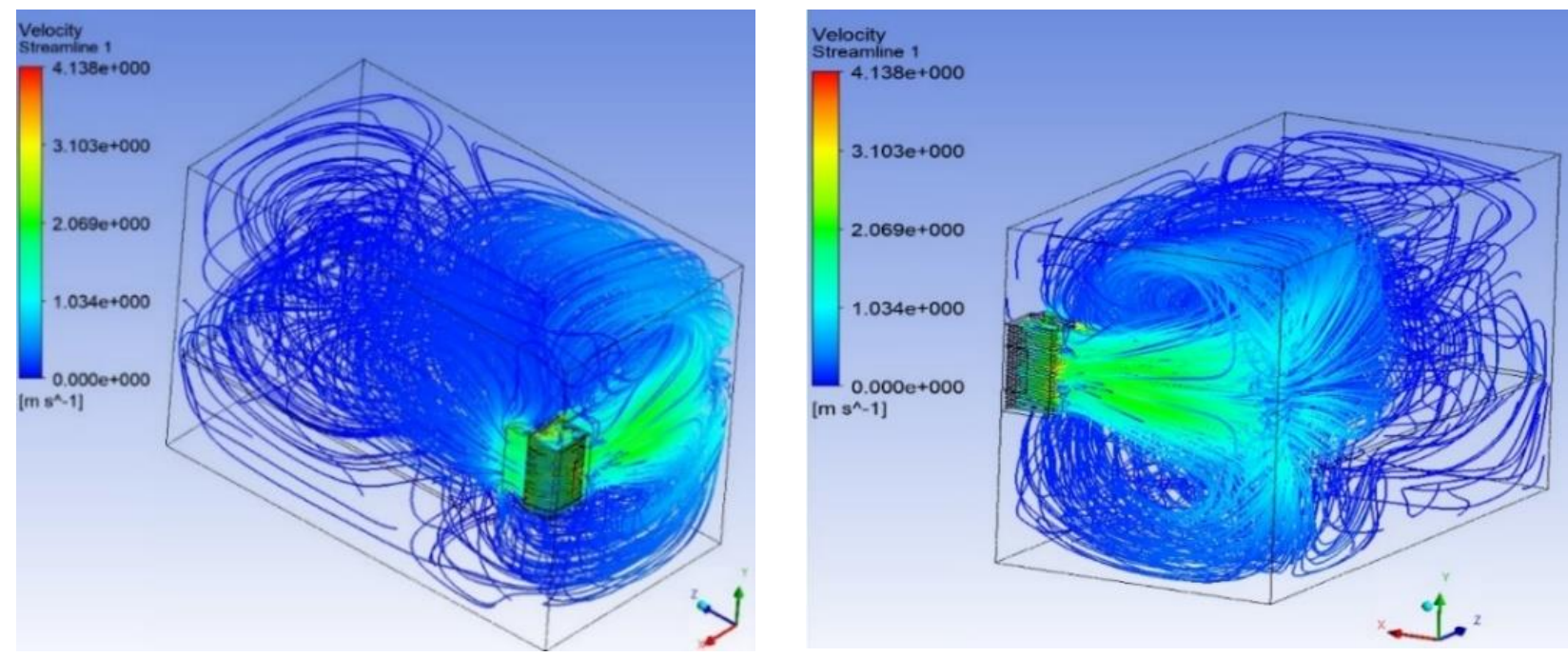

Fig. 9. Air streamlines for pushing direction-II of the fan

It can be seen that the cold regions (temperature from 275.3 to $276.8 \mathrm{~K}$ ) extended to cover most of the internal space of the thermoelectric-compartment compared with the first pushing direction of the fan. Little warm air zones can be seen beside the side and back walls, which are far from the fan. Also, this position minimized the bad effect of the presence of the shelf because the gap between the shelf and the front wall allowed the cooled air to reach the lower part of the thermoelectriccompartment.
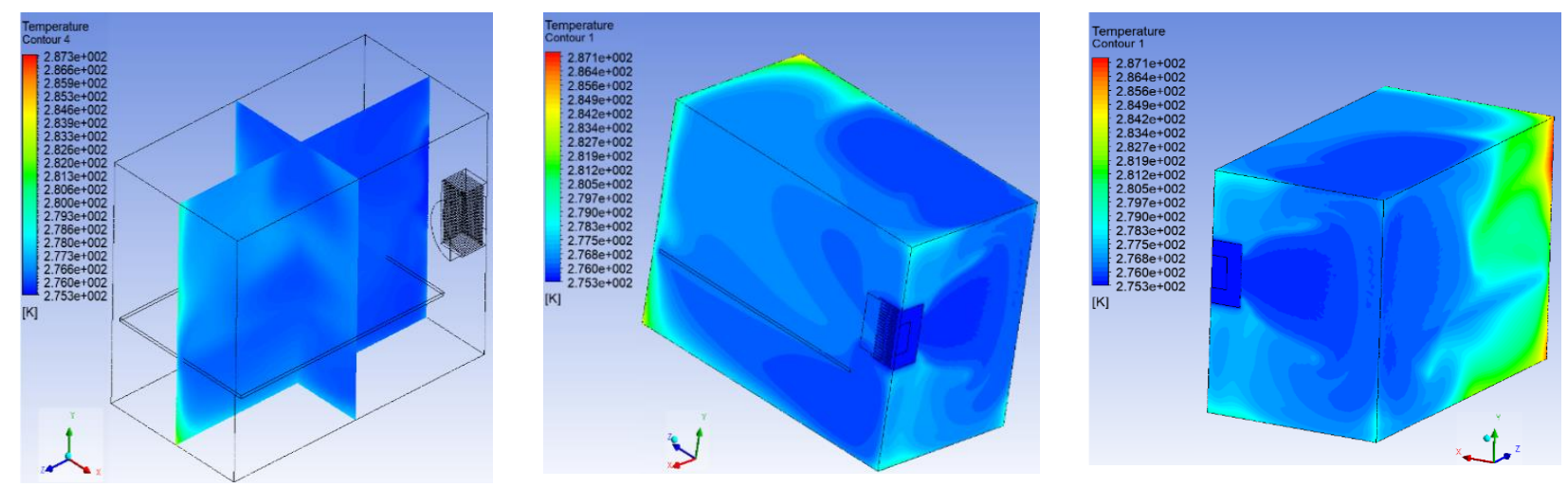

Fig. 10. Temperature distribution inside the TER compartment for pushing direction-II of the fan 
In addition to the fact that the fan pushing direction-II was associated with better air distribution, it was also more effective from the heat transfer point of view. This can be attributed to the higher heat-transfer coefficient of impinging flow over the cold heat sink compared to the air drawn through the heat sink, which was the case in fan direction-I.

\section{Conclusions}

In this work, a computational simulation of the thermal behavior of thermoelectric-compartment in a hybrid household-refrigerator, which combines the thermoelectric and vapor-compression technologies, was performed. The computational results were compared with experimental measurements and showed a good agreement. In this computational simulation, the effect of changing the pushing direction on temperature distribution was investigated. The results showed that installing the fan in a position, in which the fan pushes the air to impinge the cold-side heat sink (pushing direction-II), was more effective and it insured a good distribution for the cold-side air inside the thermoelectric-compartment. Also, it was found that the shelf played a negative role on temperature distribution in the case of fan pushing direction-I.

\section{References}

[1] Zhao, Dongliang, and Gang Tan. "A review of thermoelectric cooling: materials, modeling and applications." Applied thermal engineering 66, no. 1-2 (2014): 15-24. https://doi.org/10.1016/i.applthermaleng.2014.01.074

[2] Zsembinszki, Gabriel, Alvaro de Gracia, Pere Moreno, Ricard Rovira, Miguel Ángel González, and Luisa F. Cabeza. "A novel numerical methodology for modelling simple vapour compression refrigeration system." Applied Thermal Engineering 115 (2017): 188-200. https://doi.org/10.1016/i.applthermaleng.2016.12.059

[3] Halmy, Muhammad Syahmy Mohd, Djamal Hissein Didane, Lukmon Owolabi Afolabi, and Sami Al-Alimi. "Computational Fluid Dynamics (CFD) Study on the Effect of the Number of Blades on the Performance of DoubleStage Savonius Rotor." CFD Letters 13, no. 4 (2021): 1-10. https://doi.org/10.37934/cfdl.13.4.110

[4] Vián, J. G., and D. Astrain. "Development of a hybrid refrigerator combining thermoelectric and vapor compression technologies." Applied Thermal Engineering 29, no. $16 \quad$ (2009): 3319-3327. https://doi.org/10.1016/i.applthermaleng.2009.05.006

[5] Lu, Zhili, and Guoliang Ding. "Temperature and time-sharing running combination control strategy of two-circuit cycle refrigerator-freezer with parallel evaporators." Applied thermal engineering 26, no. 11-12 (2006): 1208-1217. https://doi.org/10.1016/j.applthermaleng.2005.10.035

[6] Söylemez, Engin, Emre Alpman, and Ayhan Onat. "Experimental analysis of hybrid household refrigerators including thermoelectric and vapour compression cooling systems." International Journal of Refrigeration 95 (2018): 93-107. https://doi.org/10.1016/i.ijrefrig.2018.08.010

[7] Cai, Yang, Yu Wang, Di Liu, and Fu-Yun Zhao. "Thermoelectric cooling technology applied in the field of electronic devices: Updated review on the parametric investigations and model developments." Applied Thermal Engineering 148 (2019): 238-255. https://doi.org/10.1016/i.applthermaleng.2018.11.014

[8] Idris, Muhammad Syafiq, Irnie Azlin Zakaria, and Wan Azmi Wan Hamzah. "Heat Transfer and Pressure Drop of Water Based Hybrid $\mathrm{Al}_{2} \mathrm{O}_{3}: \mathrm{SiO}_{2}$ Nanofluids in Cooling Plate of PEMFC." Journal of Advanced Research in Numerical Heat Transfer 4, no. 1 (2021): 1-13.

[9] Astrain, D., A. Martínez, and A. Rodríguez. "Improvement of a thermoelectric and vapour compression hybrid $\begin{array}{llll}\text { refrigerator." Applied thermal } & \text { (2012): } & \text { 140-150. }\end{array}$ https://doi.org/10.1016/i.applthermaleng.2012.01.054

[10] Lee, HoSung. Thermoelectrics: design and materials. John Wiley \& Sons, 2016. https://doi.org/10.1002/9781118848944

[11] Francis, Onoroh, Chukuneke Jeremiah Lekwuwa, and Itoje Harrison John. "Performance evaluation of a thermoelectric refrigerator." International Journal of Engineering and Innovative Technology (IJEIT) 2, no. 7 (2013): 18-24.

[12] P. K. Bansal, and A. Martin. "Comparative study of vapour compression, thermoelectric and absorption refrigerators." International Journal of Energy Research 24, no. 2 (2000): 93-107. https://doi.org/10.1002/(SICI)1099-114X(200002)24:2<93::AID-ER563>3.0.CO;2-6 
[13] Astrain, D., J. G. Vián, and J. Albizua. "Computational model for refrigerators based on Peltier effect $\begin{array}{lllll}\text { application." Applied Thermal } \quad \text { Engineering 25, no. } & \text { 17-18 } & \text { (2005): }\end{array}$ https://doi.org/10.1016/j.applthermaleng.2005.04.003

[14] Mirmanto, M., S. Syahrul, and Yusi Wirdan. "Experimental performances of a thermoelectric cooler box with thermoelectric position variations." Engineering Science and Technology, an International Journal 22, no. 1 (2019): 177-184. https://doi.org/10.1016/i.jestch.2018.09.006

[15] Martínez, A., D. Astrain, A. Rodríguez, and G. Pérez. "Reduction in the electric power consumption of a thermoelectric refrigerator by experimental optimization of the temperature controller." Journal of electronic materials 42, no. 7 (2013): 1499-1503. https://doi.org/10.1007/s11664-012-2298-9

[16] Belman-Flores, J. M., J. M. Barroso-Maldonado, A. P. Rodríguez-Muñoz, and G. Camacho-Vázquez. "Enhancements in domestic refrigeration, approaching a sustainable refrigerator-A review." Renewable and Sustainable Energy Reviews 51 (2015): 955-968. https://doi.org/10.1016/i.rser.2015.07.003

[17] Choi, Seyoung, Ukmin Han, Honghyun Cho, and Hoseong Lee. "Recent advances in household refrigerator cycle technologies." Applied Thermal Engineering 132 560-574. https://doi.org/10.1016/i.applthermaleng.2017.12.133

[18] Belman-Flores, J. M., and A. Gallegos-Muñoz. "Analysis of the flow and temperature distribution inside the compartment of a small refrigerator." Applied thermal engineering 106 (2016): $743-752$. https://doi.org/10.1016/j.applthermaleng.2016.06.065

[19] Belman-Flores, J. M., A. Gallegos-Muñoz, and A. Puente-Delgado. "Analysis of the temperature stratification of a no-frost domestic refrigerator with bottom mount configuration." Applied thermal engineering 65, no. 1-2 (2014): 299-307. https://doi.org/10.1016/i.applthermaleng.2014.01.022

[20] Ledesma, Sergio, and J. M. Belman-Flores. "Mathematical application to analyze the thermal behavior of a domestic refrigerator: Influence of the location of the shelves." International Journal of Refrigeration 74 (2017): 362-370. https://doi.org/10.1016/i.ijrefrig.2016.10.023

[21] Söylemez, Engin, Emre Alpman, Ayhan Onat, Yalçin Yükselentürk, and Selim Hartomacıoğlu. "Numerical (CFD) and experimental analysis of hybrid household refrigerator including thermoelectric and vapour compression cooling systems." International Journal of Refrigeration 99 (2019): 300-315. https://doi.org/10.1016/i.ijrefrig.2019.01.007

[22] Hebei Itd. accessed September, 2020, http://www.hebeiltd.com.cn/.

[23] Cooler Master Co. Itd. "About cooler master." accessed September, 2020, https://www.coolermaster.com/aboutcooler-master.

[24] Shenzhen Zhaoxin Electronic Instrument Equipment Co., Ltd. accessed September, 2020, http://www.zhaoxinpower.com/index.html.

[25] Yunus A.. Çengel, and Afshin Jahanshahi Ghajar. Heat and Mass Transfer: Fundamentals [and] Applications. McGraw-Hill Education, 2020.

[26] Rabby, Md Insiat Islam, Siti Ujila Masuri, Ahmad Syakir Fariz Samsul Kamal, Zulkiflle Leman, Abdul Aziz Hairuddin, and Nuraini Abdul Aziz. "Flow Characteristics of Disk Bypass Pipeline Inspection Gauge (PIG) in Natural Gas Pipelines using Computational Fluid Dynamics." CFD Letters 13, no. 4 (2021): 11-37. https://doi.org/10.37934/cfdl.13.4.1137 